\title{
Trends and Determinants of Unmet Need for Family Planning in Cameroon: The Role of Socio-Cultural Context
}

\author{
Samuel Kelodjoue
}

\begin{abstract}
This study attempts to investigate and highlight the recent trends of unmet need for family planning in Cameroon. Differences for having an unmet need by place of residence, age, marital status, education, and living standards are also assessed. It is based on Cameroon Demography and Health Surveys (CDHS) which were conducted in 1991, 1998, 2004, and 2011. It aims at declaring the women's reasons for having an unmet need and identifying the socio-economic and cultural determinants of unmet need. A high proportion of women with unmet need are those who have experienced unwanted pregnancies. Health concerns about contraceptives and social disapprovals are other important reasons. The study identifies a significant relation among the unmet need and residence, age, work status, education, living standards, knowledge about contraceptives, and children ever born. This paper finally outlines the scope for further research, offering some perspectives on the nature and socio-cultural dimensions of unmet need.
\end{abstract}

\section{Keywords}

Fertility, contraception, family planning, social pressure, Cameroon

Modern contraception is an effective way to control fertility. Despite the development and vulgarization of family planning programs for over 40 years, fertility remains high and contraceptive prevalence is low in many countries of Africa South of the Sahara: Guinea, Ivory Coast, Senegal, Cameroon, etc. In contrast, some countries such as Maurice, Cape Verde, and Rwanda within the same geographical area began their transition and contraceptive prevalence is therefore high.

The statistics indicate that sub-Saharan Africa has the highest maternal mortality and morbidity in the world with a third of all deaths of women of reproductive age being the result of a complication of pregnancy and/or childbirth. Teenage pregnancy accounts for a significant share of these maternal deaths, whilst complications of abortion, often related to unintended pregnancy, are also one of the main causes for high maternal mortality. Sub-Saharan Africa is confronted by the high levels of HIV (human immunodeficiency virus) infection in the world, particularly among the youth.

That is why low modern contraceptive use in sub-Saharan Africa remains a challenge to achieve health related Millennium Development Goals (MDGs).

aUniversity of Dschang, Cameroon

\section{Correspondent Author:}

Samuel Kelodjoue, University of Dschang, P.O. Box 134, Yaounde, Cameroon

E-mail: skelod2013@yahoo.fr 
Family planning seems to be one of the cardinal ingredients in the battle for survival as the cost is minimal and it saves lives and contributes to a significant reduction in poverty and deprivation.

Thus, policymakers and planners in all sectors should be greatly concerned about the consequences of failing to meet unmet need. To reduce the health and development consequences of unintended fertility in Cameroon, they need to be aware of women with a demonstrated unmet need for family planning and use that information to improve policies and programs.

\section{CONTEXT}

During the past four decades, the total fertility rate (TFR) in the developing world has fallen by about half, from around six births per woman to about three. However, a new analysis suggests that in much of sub-Saharan Africa, the transition from high to low fertility remains too slow. In two thirds of countries in this region, there was no meaningful change in the TFR during the interval between the two most recent Demographic and Health Surveys. In contrast, fertility has continued to decline in Latin America, Asia, and North Africa.

The socioeconomic context in which sub-Saharan Africa women live today differs from the experience of the precedents generations. The family planning needs of women have been largely ignored by the existing health services a long time ago.

Cameroon is facing the problem of rapid population growth along with the scarcity of resources which is a great hindrance to the economic growth. Increase in adolescent population and reduction in dependency ratio exhibit that phase of population transition has not got started. Cameroon has entered into the early stage of fertility transition from the past two decades. The average of more than six children per women has started to turn down. The TFR declined from 6.0 to 5.1 children in 2011

Moreover, adolescent fertility is an important phenomenon in Cameroon because of some customary practices which girls marry at a very young age. These girls who are $23 \%$ of all women of childbearing age account for almost $14 \%$ of the total fertility of women (Cameroon Demographic Health Survey [CDHS] 2011).

Generally in Cameroon, newly young married women lose independence and mobility when they move into their in-law's home after marriage. This is due to the fact that they become the new, most junior members of their marital family with little, if any, authority or autonomy, and are under strong social pressure to prove that they are a "good" daughter-in-law and wife. In some regions of Cameroon, there is a high proportion of marriage during adolescence, resulting in a high rate of adolescent childbearing. Motherhood at a very young age entails a risk of maternal mortality that far exceeds the average, and the children of young mothers tend to have higher levels of morbidity and mortality (Kamdem 2009). The adverse health consequences of adolescent fertility for both mothers and children include the high rate of maternal mortality and infant mortality. The vulnerability of adolescent girls to STDs (sexually transmitted diseases), including HIV/AIDS (acquired immune deficiency syndrome), and early childbearing also has a negative impact on the educational prospects of girls, including pregnancy-related school dropout, thereby.

Adolescent with few economic resources and those with less stable living environments are more likely than other youths to engage in sexual behaviours that put them at risk of having child contracting STD or HIV.

Early childbearing continues to be an impediment to improvements in the educational, economic, and social status of women. It is also known that contraceptive use among married adolescents is noticeably lower than among older women. And how high so far can go unmet family planning. Thus, it is important that information and services on family 
planning be made available to both married and unmarried adolescents.

The issue of family planning and its consequences are not new in Cameroon. For a number of years, there has been considerable concern about high levels of fertility and their effects on the individual and society. The emergence and rapid spread of the use of contraceptive methods among the country's population has resulted in massive campaigns to sensitise people about the seriousness of large family.

Nevertheless, because abortion law is highly restrictive in Cameroon, it is difficult to ascertain the incidence of abortion and its consequences within population in general. Therefore, there is a need to provide such services and to undertake research in understanding women sexual behaviour and reproductive health (Calves 2002). Thus, as the family planning is of growing concern today, more information is needed about the factors associated with these behaviours.

If Cameroon was able to well identify the characteristics, preferences, and intentions of these women, the factors appear to contribute more: It could make significant strides in expanding and improving family planning services to meet their needs.

\section{CONCEPTS AND BASE DEFINITIONS}

According to the Demographic Health Survey definition, a woman has an unmet need for contraception if she is fecund, sexually active, not using any contraceptive methods, and does not want a child for at least two years ("spacers") or wants no more children ("limiters").

This definition produces a conservative estimate because it excludes groups who are arguably "in need". For example, many traditional method users who are motivated and at risk of unintended pregnancies, are using traditional contraception for lack of access to more effective methods. Amenorrhea women who say that they wanted their last birth are omitted even if they wish to delay their next pregnancy.

Nevertheless, in this study, unmet need for family planning is defined as the percentage of married women who want to space their next birth or stop childbearing entirely but are not using contraception and whether or not they have the means to meet that desire.

\section{DATA AND METHODS}

Data on social, demographic, economic characteristics and family planning (methods, choice, and use) and reproductive behaviour based CDHS (1991; 1998; 2004; 2011) are used. Bivariate and multivariate techniques are used to measure the unmet need for family planning. These surveys' data have been reinforced by recent interview process which was designed to encourage open discussion about planning family. Finally, we also used results of evaluation of recent studies specially by Calves (2002) and Kamdem (2009).

\section{Descriptive Analysing of Childbearing and Contraception Use Variations}

Childbearing, fertility, and contraceptive use. Cameroon had four Demographic Health Surveys in 1991, 1998, 2004, and 2011. Among these surveys, the fertility rate or the average number of children per woman dropped from 5.8 to 5.2 and 5.1 (see Table 1). The fertility level remains high, however, the trend is downward. Thus, the crude birth rate fell from 41.2 per thousand in 1987 to 39.6 per thousand in 2005 . This trend is particularly reversed in rural areas where fertility continues to be higher (from 5.8 in 1991 to 6.5 in 2011) (see Table 1). The TFR for rural areas (5.6 births) is almost two births higher than the rate for urban areas (3.9 births). This decrease could be explained by sanitation and awareness campaigns on contraceptive methods, the effects of the economic and food crisis, and the cost of living, generally in urban areas. 
Table 1. TFR Trends in Cameroon (1991-2011)

\begin{tabular}{|c|c|c|c|c|c|c|c|c|c|c|c|c|}
\hline & \multicolumn{4}{|c|}{ Urban area } & \multicolumn{4}{|c|}{ Rural area } & \multicolumn{4}{|c|}{ Cameroon } \\
\hline & 1991 & 1998 & 2004 & 2011 & 1991 & 1998 & 2004 & 2011 & 1991 & 1998 & 2004 & 2011 \\
\hline TFR & 5.2 & 3.9 & 4.0 & 4.0 & 6.3 & 5.8 & 6.1 & 6.4 & 5.8 & 5.2 & 5.0 & 5.1 \\
\hline
\end{tabular}

Note: Sources: DHS-MICS (Demographic Health Survey-Multiple Indicators Clusters Survey) (2011); CDHS (1991; 1998; 2004).

Teenage fertility. Adolescent childbearing has potentially negative demographic and social consequences. Births that occur to teenage mothers (less than 20 years) have been found to have the highest under five mortality rate in Cameroon since the past two years (CDHS 1991; CDHS 1998; CDHS 2004; CDHS 2011). This may be due to the fact that teenage mothers are more likely to suffer from pregnancy and delivery complications than older mothers, resulting in higher morbidity and mortality for both themselves and their children. In addition, early childbearing may foreclose a teenager's ability to pursue educational or job opportunities. Table 2 shows the percentage of adolescent women (aged 15-19) who are mothers or pregnant with their first child. One in 10 teenagers has already had a child $(10 \%)$ and another $4 \%$ are pregnant with their first child. There has been no change in the overall percentage of teenage women who have begun childbearing over the last 20 years (CDHS 2011).

Urban teenagers substantially differ from their rural counterparts with respect to childbearing. Unless the percentage is decreasing in both urban and rural areas, one for two adolescent residing in rural areas has begun childbearing.

The trend analysis on teenage childbearing shows a substantial decline in adolescent childbearing, particularly in rural areas between the mid-1990s and early part of the new century (see Table 2).

According to Calves (2002), pregnancy-related complications are also higher among teenage women relative to older women. In Cameroon, where abortion may be performed legally only in cases of medical necessity or rape, a high proportion of young urban women have had at least one abortion. One in five 20-29-year-old women surveyed in Yaoundé in 1997 said that they had had an abortion. Four fifths of the procedures they reported had been performed by a physician or nurse, but the methods used were not always the safest ones, and complications were common (Calves 2002).

Age at first marriage, age at first sexual intercourse, age at first birth, and birth interval. Information on median age at first marriage, age at first sexual intercourse, age at first birth, and birth intervals provides valuable insight into birth spacing patterns. Short birth intervals that are births that occur less than 24 months apart, are detrimental to the health of both the mother and her child. Spacing children at least 36 months apart is safest and healthiest for the mother and the child. Then, longer birth intervals also contribute to smaller families by affecting reproductive pattern of women (Trussell and Menken 1978).

Table 3 shows the pattern of non-first births in the five years preceding the survey by the number of months since the previous birth. First births are omitted from the table because there is no prior birth with which to measure an interval.

There has been little change in median age at first marriage over the last 20 years. During the period 1991-2011, the average is 17.5 years. The 2011 CDHS suggests that women are waiting longer to marry and to have their first births. The age at first sexual 
Table 2. Teenager Fertility Trends in Cameroon (1991-2011)

\begin{tabular}{lllllllllllll}
\hline & \multicolumn{3}{c}{ Urban area } & \multicolumn{1}{c}{ Rural area } & \multicolumn{5}{c}{ Cameroon } \\
\cline { 2 - 12 } & 1991 & 1998 & 2004 & 2011 & 1991 & 1998 & 2004 & 2011 & 1991 & 1998 & 2004 & 2011 \\
\hline $\begin{array}{l}\text { Adolescent women } \\
\text { (aged 15-19) who are }\end{array}$ & 23.7 & 16.4 & 18.3 & 14.8 & 34.1 & 30.5 & 29.0 & 28.1 & 29.7 & 25.0 & 22.7 & 20.9 \\
$\begin{array}{l}\text { mothers or pregnant } \\
\text { with their first child (\%) }\end{array}$ & & & & & & & & & & & & \\
\hline
\end{tabular}

Note: Sources: DHS-MICS (2011); CDHS (1991; 1998; 2004).

Table 3. Insight Into Birth Spacing Patterns in Cameroon (1991-2011)

\begin{tabular}{|c|c|c|c|c|c|c|c|c|c|}
\hline \multirow{2}{*}{ Date/Period } & \multirow{2}{*}{$\begin{array}{l}\text { Median age at first } \\
\text { marriage }\end{array}$} & \multirow{2}{*}{$\begin{array}{l}\text { Age at first sexual } \\
\text { intercourse }\end{array}$} & \multirow{2}{*}{ Age at first birth } & \multicolumn{6}{|c|}{ Birth interval (months) } \\
\hline & & & & $7-17$ & $18-23$ & $24-35$ & $35-48$ & $48-59$ & $60+$ \\
\hline 1991 & 16.7 & 15.9 & 18.9 & 7.8 & 14.8 & 45.9 & 15.2 & 16.3 & \\
\hline 1998 & 17.7 & 15.9 & 19.1 & 9.6 & 15.3 & 38.2 & 19.6 & 17.4 & \\
\hline 2004 & 17.6 & 16.4 & 19 & 7.6 & 14.2 & 39.1 & 20.0 & 19.1 & \\
\hline 2011 & 18.5 & 17.0 & 19.5 & 8.3 & 13.0 & 37.3 & 19.9 & 9.3 & 12.1 \\
\hline
\end{tabular}

Note: Sources: CDHS-MICS (2011); CDHS (1991; 1998; 2004).

intercourse increased from 15.9 to 17 between 1991 and 2011 (see Table 3). However, women in 1991 start sexual activity at the median age 15.9 compared with a median age of 17 for women in 2011. The findings suggest, however, that younger Cameroonian women are more likely to begin sexual activity before marriage compared with their mothers and grandmothers (Kamdem 2009).

One of the factors that determine the level of fertility in a population is the age at first birth. Women who marry early are typically exposed to the risk of pregnancy for a longer period, especially when there is little or no contraceptive use. Thus, early childbearing generally leads to a larger family size than later onset of childbearing. A rise in the median age at first birth is typically a sign of transition from high to low fertility.

The median age at first birth varies little during the same period. In 1991, the median age at first birth is 18.9 years, in 2011, it raised at 19.5 .

There has been little change in birth spacing patterns over the last 20 years. During the period 1991-2011, the average is 17.5 years. There are no significant differences in the median birth interval by birth order. The median interval between births in 1991 is seven months longer (44 months) than women in 2011 (37 months). The median birth interval ranges from a low of 34 months in 1991 to 42 months in 2004 and 2011.

Current use of contraceptive methods. Contraceptives are used most commonly by married women between 15 and 49 years in the developing world. The current level of contraceptive use among married women has increased significantly between 1991 and 2011, from 16\% in 1991 to $19 \%$ in 1998 and $26 \%$ in 2004 . In 2011 , it slightly declined to $23 \%$ (see Table 4).

Table 4 shows trends in contraceptive use among currently married women based on the results of the four CDHS surveys (1991, 1998, 2004, 2011). Overall, contraceptive use among married women in Cameroon has nearly doubled in the past 20 years. The survey results indicate that there was a large increase in contraceptive use in the late 1991 and 2011, from $16.1 \%$ to $23.4 \%$ among married women. However, over the past 10 years, increases have been small. The 
Table 4. Trends in Contraceptive Use Among Currently Married Women Aged 15-49 (\%)

\begin{tabular}{|c|c|c|c|c|c|c|c|c|c|c|c|c|}
\hline & \multicolumn{4}{|c|}{ Urban } & \multicolumn{4}{|c|}{ Rural } & \multicolumn{4}{|c|}{ Total } \\
\hline & 1991 & 1998 & 2004 & 2011 & 1991 & 1998 & 2004 & 2011 & 1991 & 1998 & 2004 & 2011 \\
\hline $\begin{array}{l}\text { Any method } \\
\text { quelconque }\end{array}$ & 24.9 & 34.6 & 36.2 & 33.4 & 10.5 & 12.9 & 16.2 & 14.4 & 16.1 & 19.3 & 26.0 & 23.4 \\
\hline $\begin{array}{l}\text { Modern } \\
\text { method }^{1}\end{array}$ & 7.1 & 13.1 & 19.3 & 20.8 & 2.5 & 4.5 & 5.9 & 8.7 & 4.3 & 7.1 & 12.5 & 14.4 \\
\hline $\begin{array}{l}\text { Traditional } \\
\text { method }^{2}\end{array}$ & 17.9 & 21.5 & 16.9 & 12.6 & 8.0 & 8.3 & 10.3 & 5.7 & 11.8 & 12.3 & 13.5 & 8.9 \\
\hline $\begin{array}{l}\text { Not currently used } \\
\text { any method }\end{array}$ & 75.1 & 65.4 & 63.8 & 66.6 & 89.5 & 87.1 & 83.8 & 85.6 & 83.9 & 80.7 & 74.0 & 76.6 \\
\hline
\end{tabular}

Notes: 1 -female and male sterilization, pills, the intrauterine device (IUD), injection, implant, male and female condom (included LAM in 2011); 2-rhythm method/redraw except in 2011, MAMA/periodic abstinence and others; Sources: CDHS-MICS (2011); CDHS (1991; 1998; 2004).

contraceptive prevalence rate increased from $16.1 \%$ among currently married women in 1998 to $26 \%$ in 2004 , and has declined in the past five years $(23.4 \%$ in 2011), a reversal in the trend. Similarly, use of modern methods nearly doubled over the past 15 years from $4 \%$ in 1991 to $12.3 \%$ in 2004 , before increased slightly to $14.4 \%$ in 2011 . Over the past 20 years, there has been a slight decrease in the use of traditional methods. While initially there was a small increase in the use of traditional methods from $11.8 \%$ to $13.5 \%$ between 1991 and 2004 , use of these methods decreased to almost $9 \%$ in 2011. Married women in urban areas are more than twice as likely to use a modern contraceptive method as women in rural areas (see Table 4).

If the level of use of modern contraception is lower in rural areas $(9 \%)$ than urban areas $(21 \%)$, the pace of increase is everywhere the same between 1991 and 2011 (67\%). Compared with 2004, although some changes are observed timidly, the proportion of women who want no more children has increased from $12 \%$ to $26 \%$ between 1991 and 2011 , while the proportion of those who want more children increase from $32 \%$ to $35 \%$ during the same period (Table 5).

The previous four CDHS also show that the percentage of women who want more children increased by six percentage points between 1991 and
1998 (from $12 \%$ to $18 \%$ ), remained almost stable between 1998 and 2004 (18\% and 20\%), and then increased by six percentage points (from $20 \%$ to $26 \%$ ) between 2004 and 2011.

Overall, for 20 years, contraceptive prevalence is low in Cameroon. This is related to the desire of women to have as many children as possible $(37 \%$ in $2004)$, the sub fertility/infertility (16\% in 2004), the rejection of contraception (17\% in 2004) or religious prohibitions (6\% in 2004) (see Table 5).

In Table 4, we already note while the use of modern methods increases gradually, the use of traditional methods decreases. This decrease is mainly due to the decline in the practice of the rhythm method (10\% in 2004 against $7 \%$ in 2011) (see Table 5).

Among the modern methods most commonly used, there is in descending order - the male condom ( $8 \%)$, injectable ( $3 \%$, against $1.6 \%$ in 2004), and the pill $(2 \%)$.

Other modern methods are only used in less than $1 \%$ of cases during the same period.

The results of the CDHS surveys conducted over the past 20 years show that although there has been an overall decline in ideal family size among currently married women from a mean of 5.5 children in 1991 (see Table 1) to 5.1 children in 2011. There has been little change in the past 15 years. And, while there 
Table 5. Trend in Contraceptives Methods and Desire for Having Children

\begin{tabular}{lllll}
\hline & 1991 & 1998 & 2004 & 2011 \\
\hline Desire for more children & & & 37 & 66.4 \\
Desire for no more children & 12 & 18 & 20 & 26.2 \\
Primary/Sterility & 11.1 & 6.5 & 5.5 & 3.2 \\
Subfecund/Infecund & 8.3 & 2.7 & 16.3 & \\
Disapproves/Respondent opposed & 71.6 & 56.9 & 7 & \\
Cultural norms & 3.7 & 1.7 & & \\
Religions prohibition & 3.1 & 19.1 & 5.6 & \\
Condoms & .9 & 2.1 & 7.6 & 7.6 \\
Injectables & .4 & .7 & & 3.0 \\
Pills & 1.2 & 2.0 & 1.6 & 1.9 \\
Traditional method & & & & \\
Withdrawal & 1.2 & 1.6 & 2.1 & 1.8 \\
Rythmic & & & & \\
\hline
\end{tabular}

Note: Sources: CDHS-MICS (2011); CDHS (1991; 1998; 2004).

appears to have been a slight increase in ideal family size among both women and men over the past 10 years (2004), a downward trend can be seen in the five years preceding the survey. Other reasons for the unmet need are social disapprovals, socio-cultural values and norms $(3.7 \%$ in 1991) that determine the use of family planning in the country (see Table 5). On the other hand, about $19.1 \%$ (2004) of them expected rejections by religious leaders and their community to practice it.

\section{Level and Trend of Unmet Needs for Family Planning}

Potential users of family planning services. Currently married women who say that they do not want any more children or that they want to wait two or more years before having another child, but are not using contraception, are considered to have an unmet need for family planning.

Women who are using family planning methods are said to have a met need for family planning. Women with unmet need and met need together constitute the total demand for family planning.
Among these women, those who are not currently using a contraceptive method can be considered as potential candidates for family planning

Although most women in Cameroon want large families, two in five of married women $(40 \%)$ would like either to stop childbearing or to delay the next pregnancy. These women are potential users of family planning services.

The potential demand for family planning has increased steadily in Cameroon since 1991.

Compared with the previous four CDHS, the percentage of women who want to stop childbearing increased by two percentage points between 1991 and 2011 (from $38 \%$ to $40 \%$ ), remained almost stable between 1998 and 2004 (18\% and 20\%) and then increased by six percentage points (from $20 \%$ to $26 \%$ ) between 2004 and 2011 (see Table 6).

The desire to stop childbearing varies among Cameroonian women. Overall, slightly more urban women than rural women want no more children.

Likewise, the total demand for family planning did not show any substantial change. There was, however, a decrease of the six percentage points at the level of 
Table 6. Total Potential Demand for Family Planning

\begin{tabular}{|c|c|c|c|c|c|c|c|c|c|c|c|c|}
\hline & \multicolumn{4}{|c|}{ Urban } & \multicolumn{4}{|c|}{ Rural } & \multicolumn{4}{|c|}{ Cameroon } \\
\hline & 1991 & 1998 & 2004 & 2011 & 1991 & 1998 & 2004 & 2011 & 1991 & 1998 & 2004 & 2011 \\
\hline Space & 31.5 & 28.9 & 38.4 & 36.4 & 18.4 & 14.4 & 25.7 & 25.5 & 23.4 & 23.0 & 29.9 & 28.6 \\
\hline Limit & 17.2 & 18.8 & 17.3 & 19.6 & 13.0 & 11.5 & 11.4 & 13.7 & 14.6 & 10.6 & 10.7 & 11.6 \\
\hline Total & 48.7 & 47.6 & 55.7 & 56.1 & 31.4 & 25.9 & 37.1 & 38.7 & 38.0 & 33.6 & 40.6 & 40.3 \\
\hline
\end{tabular}

Note: Sources: CDHS (1991; 1998; 2004).

demand satisfied: from $33.6 \%$ in 1998 to $40 \%$.

A comparison of the findings from the four CDHS surveys shows that the desire to limit births among currently married Cameroonian women in rural area has declined while the desire to space births has risen. Over the past 20 years, the desire to space births has increased from $45 \%$ in 1991 to $36 \%$ in 2011, however, this change has been minimal in the past 10 years. Over the same period, the desire to limit births (excluding sterilised women) has increased from 23\% in 1991 to $35 \%$ in 2004. Again, this change has been minimal over the past 10 years.

Unmet need for family planning trend in Cameroon. Women in union are not contraceptive users who say they want no more children (birth control) or who say they want to wait at least two years before the next birth (spacing) are considered to have unmet need for family planning.

However, according to Table 7, the unmet need for family planning among married women has hardly dropped down (changed) during the period (22\% in 1991 and $16.6 \%$ in 2011).

Table 7 shows comparison of data from the 1991 and 2011 CDHS surveys, suggests that there has been little change in the unmet need among currently married women over the past 20 years. Likewise, the total demand for family planning did not show any substantial change. There was, however, a decrease of three percentage points at the level of demand: from $22 \%$ in 1991 to $9.6 \%$ (see Table 7). Unmet need is somewhat higher in rural areas $(20.9 \%)$ than in urban areas (19.5\%), but is high in both.

Rural women have a higher unmet need for family planning than their urban counterparts (38\% compared with $28 \%$ ). It is also interesting to note that rural women have higher unmet need for both spacing and limiting than their urban counterparts.

When unmet need is so high, there is a demand for services throughout society. There is a need to expand and improve family planning services in both urban and rural areas.

\section{Characteristics of Women With Unmet Need in Cameroon}

Critical examination of married women by their reproductive health characteristics showed that the proportion of individuals with an unmet need for family planning (i.e., who have a current unwanted pregnancy or who are fecund, are sexually active, want no more births but are not using contraceptives) is as high as $16 \%$ (see Table 7). Considerable within regions, place of residence, education, living standards, and children ever born variations are seen during the last 20 years. Moreover, unmet need increases with age, suggesting an unmet need for limiting rather than for spacing births.

Unmet need appears to be high among women of all educational backgrounds. Women who have attained four years of secondary education or more have a lower unmet need than other women, but only a small proportion of women achieve this level of education in Cameroon. 
Table 7. Unmet Need for Family Planning

\begin{tabular}{|c|c|c|c|c|c|c|c|c|c|c|c|c|}
\hline & \multicolumn{4}{|c|}{ Urban } & \multicolumn{4}{|c|}{ Rural } & \multicolumn{4}{|c|}{ Cameroon } \\
\hline & 1991 & 1998 & 2004 & 2011 & 1991 & 1998 & 2004 & 2011 & 1991 & 1998 & 2004 & 2011 \\
\hline Space & 14.3 & 6.6 & 12.9 & 14.6 & 11.2 & 6.7 & 15.4 & 16.4 & 12.4 & 5.1 & 10.3 & 11.2 \\
\hline Limit & 9.5 & 6.5 & 6.6 & 8.1 & 9.7 & 6.4 & 5.5 & 7.9 & 9.6 & 4.5 & 4.2 & 5.3 \\
\hline Total & 23.7 & 13.1 & 19.5 & 22.7 & 20.9 & 13.0 & 20.9 & 24 & 22.0 & 9.6 & 14.5 & 16.6 \\
\hline
\end{tabular}

Note: Sources: CDHS-MICS (2011); CDHS (1991; 1998; 2004).

Table 8. Characteristics of Women With Unmet Need in Cameroon

\begin{tabular}{|c|c|c|c|c|c|c|c|c|c|c|c|c|c|c|c|c|c|c|c|c|}
\hline \multirow[b]{2}{*}{$\begin{array}{l}\text { Date/ } \\
\text { Period }\end{array}$} & \multicolumn{5}{|c|}{ Wealth } & \multicolumn{4}{|c|}{ Place of residence } & \multicolumn{7}{|c|}{ Age group } & \multicolumn{4}{|c|}{ Education } \\
\hline & $1 / 5$ & $2 / 5$ & $3 / 5$ & $4 / 5$ & $5: 5$ & $\mathrm{D} / \mathrm{Y}$ & $\begin{array}{l}\text { Autres } \\
\text { ville }\end{array}$ & Urban & Rural & $15-19$ & $20-24$ & $25-29$ & $30-34$ & $35-39$ & $40-45$ & $45-49$ & Aucun & Primaire & $\begin{array}{l}\text { Soncond } \\
\text { aire } 2 \text { nd } \\
\text { 1st cycle }\end{array}$ & $\begin{array}{l}\text { Soncondaire } \\
\text { 2nd 1st } \\
\text { cycle et plus }\end{array}$ \\
\hline 1991 & & & & & & 22.0 & 24.7 & 23.7 & 20.9 & 15.1 & 21.9 & 18.3 & 20.8 & 29.4 & 26.33 & 27.3 & 20.4 & 25.8 & 19.4 & \\
\hline 1998 & & & & & & 11.3 & 14.1 & 13.1 & 13.0 & 11.5 & 11.1 & 11.2 & 12.4 & 18.3 & 18.1 & 10.1 & 12.8 & 13.2 & 15.1 & 10.3 \\
\hline 2004 & 19.0 & 22.6 & 23.7 & 20.0 & 16.2 & 18.4 & 20.1 & 19.5 & 20.5 & 19.5 & 21.7 & 18.9 & 20.8 & 24.3 & 19.7 & 13.0 & 19.8 & 22.7 & 17.4 & \\
\hline 2011 & 25.7 & 23.9 & 25.4 & 23.7 & 19.2 & 21.2 & 23.7 & 22.7 & 24.3 & 25.7 & 24.8 & 23.3 & 24.6 & 24.0 & 23.3 & 16.7 & 23.2 & 26.2 & 23.4 & 16.9 \\
\hline
\end{tabular}

Note: Sources: DHS-MICS (2011); CDHS (1991; 1998; 2004).

Women with secondary or higher education have a lower unmet need for family planning (24\%) than women with primary education and those with no education whose unmet need for family planning is $40 \%$ and $35 \%$, respectively. Total demand for family planning is the highest for women with primary education rather than women with no education, $66 \%$ compared with $50 \%$. The percentage of demand satisfied ranges from $30 \%$ among women with no education to $62 \%$ for women with secondary or higher level education.

Women's educational status is positively associated with contraceptive prevalence rate in the study district. Longer years of education could probably give married women better chance to understand uses of contraception to reduce fertility, maternal and child morbidity, and mortality. It might also increase awareness on the side effects of contraceptive methods to prefer the most convenient ones.

CDHS responses can be used to divide households into wealth classifications: the lowest, second, middle, fourth, and highest. This does not mean that households in the "highest" group are wealthy, but rather that they have access to relatively more resources than the other households in the sample. In urban areas, women in wealthier households have less unmet need than women in poorer households. In rural areas, there is no relationship between household wealth and unmet need.

The unmet need for family planning is the highest among women in the lowest wealth quintile and the lowest among women in the highest wealth quintile ( $41 \%$ and $24 \%$, respectively). For all the five wealth quintiles, the unmet need for spacing is higher than the unmet need for limiting. Also, the percentage of demand satisfied ranges from $26 \%$ for women in the lowest wealth quintile to $59 \%$ for women in the highest wealth quintile.

Multivariate analyses confirm most of these results. Table 8 showed the bi-variate and multivariate association of various background characteristics of married women with the unmet need in family planning during the last 20 years. The odds of current 
use of family planning was 2.3 (95\% CI: $1.66,3.18)$ times higher in 2011 compared with 1991. However, the odds of the unmet need in family planning services between 2004 and 2011 were eliminated when other background characteristics of women were included in the model. There was a positive association between with the unmet need in family planning and educational status of women. Women with primary and secondary level of education were about 1.32 (95\% CI: 1.12, 1.56) and 1.99 (95\% CI: 1.38, 2.88) times, respectively, more likely to use family planning compared to their uneducated counterparts.

\section{Role of Socio-Cultural Context}

Social and cultural background of reproduction in Africa tends to promote the existence of large families. In the ancient cultural model in Cameroon, education strategies to life in general and sexual transmission standards in the major ethnic groups were much work of seniors in homogeneous and unisexual groups than those of parents/guardians.

In Cameroon, normative referents and sociocultural form of transmission vary by ethnic group and sex of individuals. For example, for Bamiléke peoples (western region, Cameroon), sexual permissiveness and premarital sexual earliness behaviours traditionally were subject to social sanction. For fear of reprisals, young (especially the girl) received a very rigid education, where education of the subject of men and sexuality were taboo subjects. This in contrast with some other ethnic groups like Beti/Fan (centre and southern regions).

These different socio-cultural practices to facilitate the transmission of information about life in general and about sex and its consequences in particular, however, lost their relevance with the modernization of society and the breakdown of community stress. Socialization of sexual life has become mostly the work of smaller family. However, parents find it difficult to fill this education. Due to family pressures, couples start planning the child soon after marriage irrespective of their education, work status, and wealth index. Couples appear to be under social pressure to prove their fertility by bearing a child within a short time after marriage.

Socio-cultural context relating to unmet need includes (see Table 9):

(1) Economic factors which concern costs and hidden costs (time constraints) for women and belief in rumours pertaining to the methods, especially fear of future barrenness can delay impedance to services;

(2) Religious and cultural barriers (marital age) and multiplicity of religious interpretations with respect to the role of family planning in the life of the faithful. Insensitivity to each other's religious needs, non-natural family planning is forbidden by the church and Islamic religion is more tolerant and favours the use of methods of contraception within the ambit of marriage (exceptions in certain Islamic groupings). It is important that religion should help each young people who are not necessarily religious;

(3) Social norms in terms of sexuality emphasized negative image about women who use contraceptives as these are not in keeping with the primary role of the woman: to give birth;

(4) Traditional mechanism for the regulation of births and taboos around breast feeding (incompatibility in having sexual relations while breastfeeding), etc.

For most women in Cameroon, the use of a modern method of contraception is first and all a social act. Therefore, it implies the approval or the support of the partner and other influential members of the family (mothers in law). For women in the rural communities or those who are not economically independent, the approval or the consent of the partner (spouse) is unavoidable. This situation has to be understood within the social and cultural context of reproduction in Africa and the impact of this background on family planning needs.

Surveys have proven that when women participate in decisions at home, they are more likely to use 
Table 9. Religious and Cultural Factors or Barriers of Contraceptive Use

\begin{tabular}{|l|l|l|}
\hline Topics & Sub-topics & Problems/Obstacles/Barriers \\
\hline Socio cultural factors & Gender & $\begin{array}{l}\text { Low women's social status } \\
\text { Low access to adequate information }\end{array}$ \\
\hline & Economics/Education & $\begin{array}{l}\text { Lack of women's empowerment-education/economic } \\
\text { Low level of comprehensive education on family planning at all levels }\end{array}$ \\
\hline Leadership & $\begin{array}{l}\text { Multiplicity of religious interpretations with respect to the role of family } \\
\text { planning in the life of the faithful } \\
\text { Insensitivity to each other's religious needs }\end{array}$ \\
\hline & $\begin{array}{l}\text { Religious and cultural barriers (marital age) } \\
\text { Lack of/Inadequate legislative framework conducive to family planning }\end{array}$ \\
\hline $\begin{array}{l}\text { Legal policy } \\
\text { commitical } \\
\text { society }\end{array}$ & $\begin{array}{l}\text { Lack of political understanding of unmet family planning needs of women, } \\
\text { men, and youth and of their link with development } \\
\text { Lack of framework for public-private partnership }\end{array}$ \\
\hline
\end{tabular}

Note: Source: the author's synthesis.

contraceptives. In Cameroon, there is evidence of not using contraceptives at the start of marriage (see Table 4). A woman has to prove her fecundability, so couples start planning the child soon after marriage irrespective of their education, work status, and wealth index status. When women earn income and contribute financially to the management of the home, they also participate in decision-making.

But age at marriage is difficult to increase due to effect of strong social customs on it.

There is need of effective family planning policies to increase the length of first birth interval along with delayed marriages to get a significant control over rapid population growth. Age of women at marriage and age of women at the birth of first child have played vital role in its determination. Modernization factors have not affected negatively the length of first birth interval.

First birth interval is inconsistent and irregular due to cultural norms and bans of society (Sanajaoba, Sharat, and Narendra 2011). Marriage to first birth interval is not governed by urbanization and modernization factors but depends on social norms and taboos. For example, even presence of mother-in-law at home and joint family system affect length of birth interval (Khan and Raeside 1998). The same is the case of marriage to first birth interval for current data.

Education of husband is an important factor particularly in those societies where woman takes her reproductive decision with the consent of her husband. Gender composition also influences birth interval (Maitra and Pal 2004).

\section{DISCUSSIONS}

Strong evidence exists that there is a high level of unmet need for family planning in Cameroon. Family planning seems to be one of the cardinal ingredients in the battle for survival as the cost is minimal and it saves lives and contributes to a significant reduction in poverty and deprivation.

This study also established the influence of social pressure on women to prove their fertility.

Although the estimation of "unmet need" results from fertile women who are sexually active and do not use contraception and yet want to space births at least two years or would like to limit births. It admits too many possibilities and lacks sufficient clarity in all socio-cultural contexts. It is necessary to further investigate the nature of community interaction and also on other factors in the community that are 
conducive for fertility reduction. Such information, however, is difficult to gather from a survey data as it involves collecting information from hundreds of heterogeneous clusters and communities.

"Wanted" fertility, which is calculated on the basis of whether the last birth was wanted, is different from "ideal family size", which is a separate question. According to some DHS findings, a majority of sub-Saharan African countries (many of them with the lowest TFRs in the region) actually have desired family sizes larger than the TFRs.

The consequence of unmet need individual and family levels is the most obvious result of unmet need for family planning, represented by a high rate of unwanted, unplanned, or unintended pregnancies. Many of these must have ended in unsafe abortion, and contributed to maternal mortality. Africa has the highest maternal mortality ratios in the world. Such ratios reflect a measure of unwanted pregnancy.

Other categories of unmet need may include:

(1) Fertile women who are sexually active, use traditional methods (which are unreliable) and lack access to modern methods;

(2) Women who use a method of contraception but are likely to abandon it at any time for various reasons - either by choice or for problems of inadequacy;

(3) Women in post-partum amenorrhoea whose previous pregnancy was a desired one and wants to wait for a two-year period before a new pregnancy.

If these women are included, the unmet need in sub-Saharan Africa increases from $26 \%$ to $43 \%$. The consequences of unmet need include pregnancies that are not spaced, high risk pregnancies (abortions, deaths, morbidity, and after effects), and increased rate of rapid population growth. Often the unmet need is related to availability, accessibility, or quality of services. They may also be due to true or mythical beliefs about safety and efficacy of the methods. If the definition was expanded to include women using traditional methods because they had no access to modern methods, and women in amenorrhea who want to space or limit, the size of unmet need would substantially increase.

The "unmet need for family planning" is narrowly defined in DHS surveys as to assess the number of potential clients. It is defined as the percentage of women of reproductive age who claim they do not want any more children, or that they want to wait a certain number of years before having the next child and who are however not using any contraception to support their wish.

The benefits of meeting the needs include the level of current use of contraceptive methods which is one of the indicators most frequently used to assess the success of family planning programme activities. It is also widely used as a measure in analysing the determinants of fertility.

Health concerns about contraceptives and social disapprovals are other important reasons. Interestingly, inadequate access to services and lack of knowledge about methods and outlets are not among the predominant causes of unmet need.

The fertility decline is occurring in the context of increasing use of modern methods of contraception. Data on fertility trends show that fertility began to decline 10-15 years before the survey, which coincides with the introduction of the family planning.

Because abortion law is highly restrictive in Cameroon, it is difficult to ascertain the incidence of abortion and its consequences in within population in general.

Data on unmet need, supplemented with information on induced abortion and related issues, could provide countries with useful inputs for formulating and implemented responsive reproductive health policies and programs.

\section{CONCLUSIONS}

In conclusion, current family planning use among married women in Cameroon is still low, though the 
unmet need is very high. Thus, the commitment of the Cameroon Government to achieve an 50\% contraceptive demand satisfaction by 2015 is far to reach since about $71 \%$ of married women who have four surviving children desire to have more children and the desire is even higher in rural areas.

Considerable information exists about the characteristics, intentions, and preferences of women with an unmet need for family planning services. These characteristics differ from region to region and socialization area.

Some key points emerge from this study.

First, there is a very high level of unmet need for family planning services in Cameroon. The continuing prevalence of adolescent marriage and low contraceptive use during adolescence, resulting in a high rate of adolescent fertility. The adverse health consequences of family planning for both mothers and children include the high rate of maternal mortality and infant mortality.

Second, failing to respond to unmet need has serious consequences. By addressing unmet need, the country can improve the health of mothers and their children and families provide couples with the ways and means to decide the size and spacing of their families, and contribute to the overall social and economic development effort. Conversely, the failure to address unmet need would forfeit these advantages. In a context where abortion is highly restricted and uncommon among young women with regard to abortion practices, decision-making processes, health risk, and motivations.

Third, policymakers and program managers need to use available information to develop appropriate policies, strategies, and programs that will improve services and remove obstacles to family planning use by women with a demonstrated unmet to develop appropriate policies, strategies, and programs that will improve services and remove.

Expanding and improving family planning services would help respond to the expressed desires of Cameroonian women and would be good public policy.

From the preceding socio-cultural analysis, many obstacles related to unmet need can be removed with appropriate policies, strategies, and programmes using the available information on unmet need.

These strategies and programs should include:

(1) Adopting a participatory approach for the implementation of family planning programs;

(2) Soliciting the support of the community, the husband, and the leaders as a product of all family planning programs, men should be specifically targeted;

(3) Giving high priority to social mobilization of the leaders and members of the community, especially regarding teenagers who have unmet need;

(4) Improving the social status of women and young girls by integrating their economic activities and incorporating the gender dimension in family planning programs and the social status of women;

(5) Focusing the interventions on the post-natal period and suggesting appropriate methods of contraception to them;

(6) Developing the messages to promote the use of contraception and the resumption of sexual relations during the post-partum and breastfeeding periods.

\section{References}

Akam, E. 1991. "Teenager Childbearing in Cameroon Rural Area." IFORD Papers (Les Cahiers de l'IFORD) 16:117.

Ashford, L. 2003. Unmet Need for Family Planning: Recent Trends and Their Implications for Programs. Washington, D.C.: Population Reference Bureau.

Bella, N. 1995. "Fertility in Cameroon: Levels and Trends." Population 50(1):35-60.

Bledsoe, C. H. and B. Cohen, eds. 1993. Social Dynamics of Adolescent Fertility in Sub-Saharan Africa. Washington D.C.: National Academic Press.

Bongaarts, J. 1978. "A Framework for Analyzing the Proximate Determinants of Fertility." Population and Development Review 4(1):105-132.

. 1980. "The Fertility Inhibiting Effects of Intermediate Fertility Variables." Working Papers, Center for Policy 
Studies, New York.

. 1981. "The Impact on Fertility of Traditional and Changing Child-spacing Practices." Pp. 111-132 in Child-spacing in Tropical Africa: Traditions and Change, edited by H. J. Page and R. Lesthaeghe. New York: Population.

Bongaarts, J. and R. Potter. 1983. Fertility, Biology and Behaviour. New York: Academic Press.

Bongaarts, J., O. Frank, and R. Lesthaeghe. 1984. "The Proximate Determinants of Fertility in Sub-Saharan Africa." Population and Development Review 10(3):511-537.

Calves, A. E. 1996. "Youth and Fertility in Cameroon: Changing Patterns of Family Formation." Ph.D. thesis, The Pennsylvania State University.

2002. "Abortion Risk and Decision-making Among Young People in Urban Cameroon." Studies in Family Planning 33(3):249-260.

Cameroon. 1983. "Cameroon National Fertikity Survey, 1978." Rapport Principal. Yaoundé: Department of Statistics and National Accounts.

- 1992. "Cameroon Demographic Health Survey 1991." National Department of the Second General Census of Population and Housing/DHS.

—. 2004. "Cameroon Demographic Health Survey 2004." DHS Working Papers. Macro International Inc.

—. 2012. "Demographic Health Survey-Multiple Indicators Clusters Survey, 2011.” DHS Working Papers. Macro International Inc.

Fotso, M. and B. Barrere. 1999. Cameroon Demographic Health Survey 1998. Calverton, M.D.: Central Bureau of Censuses and Population Studies and Macro International, Inc.

Kamdem, H. 2009. "Knowledge, Attitudes and Practices of Young People in Relation to Abortion in Large Towns in Cameroon: Evaluation Based on Survey Data." Presented at the Communication, XXVI Congress of the Population Organized by the International Union for the Study of Population (IUSSP). November, Marrakech (Maroc).

Kelodjoue, S. and L. Moyo. 2009. "Induced Abortion in Cameroon: Between the Clandestiness and the Legality." Presented at the Communication, XXVI Congress of the Population Organized by the International Union for the Study of Population (IUSSP). November, Marrakech (Maroc).
Khan, H. T. and R. Raeside. 1998. "The Determinants of First and Subsequent Births in Urban and Rural Areas of Bangladesh." Asia-Pacific Population Journal 13(2):39-72.

Kuate-Defo, B. 1998. Sexuality and Reproductive Health in Adolescence in Africa With a Focus on. Ediconseil, Montréal.

Maitra, P. and S. Pal. 2004. Birth Spacing and Child Survival: Comparative Evidence From India and Pakistan. Retrieved (http://128.118.178.162/eps/lab/papers/0403/0403023.pdf).

Sanajaoba, S. N., S. N. Sharat, and R. K. Narendra. 2011. "Demographic and Socio-economic Determinants of Birth Interval Dynamics in Manipur: A Survival Analysis." Online Journal of Health and Allied Sciences 9(4):3.

Trussell, J. and J. Menken. 1978. "Early Childbearing and Subsequent Fertility." Family Planning Perspectives 10(4):209-218.

Trussell, J., L. G. Martin, R. Feldman, J. A. Palmore, M. Concepcion, and D. Noor Laily Bt. Dato' Abu Bakar. 1985. "Determinants of Birth-interval Length in the Philippines, Malaysia, and Indonesia: A Hazard-model Analysis." Demography 22(2):145-168.

USAID (United States Agency for International Development). 2005. "Perspectives on Unmet Need for Family Planning in West Africa: Cameroun." Presented at the Responding Family Planning in West Africa. February 15-18, Accra, Cameroon.

Yana, S. 1995. Seaking Cultural Models of Fertility in Cameroon: An Exploratory Study With Bamiléké and Beti of Urban and Rural Areas. Demography Institute of the Catholic University of Louvain, Louvain-la-Neuve, Academia, Harmattan.

\section{Bio}

Samuel Kelodjoue, Ph.D., senior lecturer, researcher, Demography/Population Sciences and Environment and Development at Population Research and Training Centre, University of Dschang, Cameroon, CRVS Internationnal Consultant (UNECA); research fields: civil registration and vital statistics systems, population projections, analysis of fertility and mortality, migration, labor force dynamics and human capital, population agriculture and the environment, aging, and population approaches to health disparities and data dissemination. 